\title{
A Cross-Cultural Comparison of Self-Regulated Learning Skills between Korean and Filipino College Students
}

\author{
Joanne P. Turingan \\ Pampanga Agricultural College \\ 85 San Paolo, Magalang, Pampanga, Philippines \\ Yong-Chil Yang (Corresponding author) \\ Andong National University \\ Andong, Kyungbuk 760-749, Korea \\ Tel: 82-54-820-5585Ｅ-mail: ycyang@andong.ac.kr
}

\begin{abstract}
This study investigated a cross-cultural comparison of self-regulated learning (SRL) skills between Korean and Filipino college students. Specifically, it identified and analyzed the motivational and learning strategies adopted by Korean and Filipino students. To measure their SRL skills, the Motivated Strategies for Learning Questionnaire was administered. Results of this study showed that the degree of Filipino students' SRL skills was higher than one of Korean students. Cultural and educational contexts of the two countries were examined to identify possible factors underlying the differences between two countries' college students in SRL skills.
\end{abstract}

Keywords: Self-regulated learning, Cross-cultural comparison, College student

\section{Introduction}

The constructivist approach to learning has been favoured as an explanation of how people learn. Constructivism views learners not as one who is passively instilled with information and knowledge but one who are actively involved in organizing and reconstructing their existing knowledge with new knowledge (Perkins, 1992). Several attempts to study how students approach their learning have been made. There are consistencies in the findings of previous studies which manifest that self-regulated learning (SRL) skills plays an important role in learning processes (Purdie and Hattie, 1996; Zimmerman and Schunk, 2001). While these studies have greatly contributed to our understanding of human learning processes, majority of them have been done in the Western contexts (Purdie, 1995). Tynjala (1997) suggested that the Western studies on SRL consider learning as a very narrow instrumental perspective.

Moreover, most of the studies which take into account the pivotal effects of SRL in academic settings have focused on K-12 students (Vanderstoep et al., 1996; Pintrich, 1995). The present study focuses on college level, for a reason that researches on SRL are more relevant to college students than K-12 students. This is supported by the idea that college students are more disposed to control their time schedule, and decide how they approach their learning than K-12 students (Chye et al., 1997). It had been further observed that college students need guidance in order to balance the academic and social life (Pintrich, 1995). It is required to conduct a comparative study on the use of college students' SRL skills from other cultural backgrounds.

The need for cross-cultural understanding of relationships between conceptions of learning and the use of learning strategies is becoming increasingly important because of the changing cultural mix of our classroom and society at large. To keep up with this ongoing trend, it is required to further explain the role of culture on differences in SRL behaviour. It is done by probing into the educational experiences of the culturally diverse students in order to investigate the factors that may have contributed to the divergence. Saljo (1987) acknowledges that the variance inherent to the different socially and culturally established conventions with respect to what constitutes learning. Differences in culture bring about diversity to styles of thoughts and values; consequently perceptions and strategies applied in learning vary 
accordingly. According to Pillay et al., Erase (2000), cross cultural studies have assisted in identifying monoculture bias and developed an improved understanding of different aspects of learning processes.

This study aimed to investigate how Korean and Filipino college students regulate their own learning processes. Specifically, it made a cross-cultural comparison on self-regulated learning skills between Korean and Filipino college students.

\section{Review of Related Literature}

\subsection{Self-Regulated Learning and Academic Achievements}

The term of self-regulated learning (SRL) has become popular from the 1980's, since it emphasizes the student autonomy to take charge of his/her own learning. As a general term, it subsumed research on cognitive strategies, metacognition, and motivation in one coherent construct that focuses on interactions among these forces. It is regarded as a valuable term, because it explains how the "self" is the agent in establishing learning goals, and how each individual's perceptions of the self and tasks have effects upon the quality of learning.

SRL behaviour is often interpreted in the light of students' use of learning strategies for the self-regulation of cognition and behaviour (Garcia, 1995). It is considered as an important aspect of students' learning and academic performance (Corno \& Mandinach, 1983). In addition, Gitomer and Glaser (1987) proposed that SRL strategic response to perceived difficulty, recognizing limitations on knowledge resources, and taking time to make transformations are necessary in a problem space to permit one to operate well. Pintrich and Garcia (1992) suggested that SRL is defined by students' use of deeper processing strategies like elaboration and planning as their use of metacognitive control strategies. Pintrich (1995) described self-regulation as the active, goal-directed self-control of behavior, motivation, and cognition for academic tasks by an individual student.

SRL has been used to describe learning that is guided by metacognition, strategic action and motivation to learn (Perry et al., 2006; Winne \& Perry, 2000). In particular, self-regulated learners are cognizant of their academic strengths and weaknesses, and they have a repertoire of strategies to be applied to tackling the day-to-day challenges of academic tasks. These learners hold incremental beliefs about intelligence (as opposed to fixed views of intelligence), and attribute their successes or failures to factors (e.g., effort expended on a task, effective use of strategies) within their control (Dweck, 2002). Finally, self-regulated learners believe that opportunities to take on challenging tasks, to practice their learning, to develop a deep understanding of subject matter, and to exert efforts, will give rise to academic success (Perry et al, 2006). Most recently, Schunk and Zimmerman (2008) defined SRL as the process by which learners personally activate and sustain cognitions, affects, and behaviors that are systematically oriented towards attainment of learning goals. In summary, SRL skills helps to describe the ways of how students approach tasks, apply strategies, monitor their performance, and interpret the outcomes of their efforts towards achieving specific learning goals.

\subsection{Cross-Cultural Studies on SRL}

In cross-cultural studies on SRL, the focus is more often on the concept of control and its differences between Asian and Western learners (Purdie and Hattie, 1996). Western scholars tend to describe Asian learners for being reactive rather than proactive in their approaches to learning. Asian learners are observed to be more dependent on their teacher's instruction rather than initiating on their own learning.

Cultural comparison research showed that Japanese students were more reliant on external sources of control than American students (Tanaka-Matsumi \& Marsella, 1976). It means that students' academic achievements are deeply related with their cultural characteristics. For instance, Japanese culture is depicted as emphasizing interdependency, while American culture is pictured as emphasizing individuality. The results of another research on the difference in the use of learning strategies between Singaporean and Australian students support the fact that cultural factors have strong relations with students' SRL behavior (Chen and Stevenson, 1995).

\subsection{Comparisons of Korean and Philippines' apostrophe use Culture and Education}

Eastern Asians value their children's academic grades more highly than cognitive development for their progress. They believe that those grades realistically reflect their children's future success (Stevenson \& Lee, 1991). Therefore, the role of a parent has been perceived as monitoring their children's homework regularly, and keeping higher expectation for child education (Strom et al., 1988). Generally, Eastern Asian students are highly motivated by a strong desire for upgrading their socioeconomic status, upholding family honor, acquiring admiration from their teachers and parents, and getting a good job (Siu, 1992).

Wollam (1992) stressed how Eastern Asian culture demands careful parental monitoring of children's academic progress. Researches have shown the significance of the parental engagement on a student academic achievement. Wollam (1992) also indicated that, "in spite of this extraordinary commitment to education, South Korean educators recognize the deficiency of a rigid Korean educational system, which culminates in a difficult college entrance 
examination." (p. 22). There is an extreme competition on college entrance examinations, which is also closely related to the limited opportunity for favored white-collar jobs. The Korean educational system culminates in one of the most elite selection processes in the world with emphasis on equality of curriculum and instruction. He pointed out that Korean society places such a high priority on the college degree.

The university entrance system in South Korea is highly competitive, and it has undergone many changes. Students are selected for admission to an institution of higher education based on the results of the Scholastic Achievement Examination for College Entrance (SAECE). This score, with the student's high school transcript, determines college admission. Preparation for the SAECE is a grueling ordeal for the students, and it is not uncommon for some families to employ private tutorials outside the classroom to ensure their children's success on the exam.

Savada and Shaw (1992) described a college-bound Korean high school student, in the late 1980s, typically rose at dawn, did a bit of studying before school began at 7:30 or 8:00 am, attended school until 5:00 pm, had a quick dinner (often away from home), and then attended evening cramming classes that could last until 10:00 or 11:00 pm. Even Sundays and holidays were devoted to more cramming. Because tests given in high school (generally once every two or four weeks) were almost as important in determining college entrance as the final entrance examinations, students had no opportunity to relax from the study routine. Family and social life are generally sacrificed to the supreme end of getting into the best university possible.

On the other hand, Philippine education system is patterned after the American system, with English as the medium of instruction. Schools are classified into public (government) or private (non-government). The general pattern of formal education follows four stages: 1) Pre-Primary Level (Nursery and kindergarten) offered in most private schools; 2) Six years of Primary education followed by 3) Four years of Secondary education; and 4) College education which usually takes four years, or five in some cases as in medical and law schools, as long as eight years. Graduate schooling is an additional two or more years. Due to these educational institutions and the people's passion for education, the literacy rate in the Philippines is now 89.9\%, the highest among Southeast Asian countries. Metro Manila has an even higher literacy rate of $96 \%$ with a student population of 2.5 million (CHED, 2007).

The information from the Commission of Higher Education (CHED, 2007) suggests that the structure of the tertiary system in the Philippines, in terms of awards and style of programs offered, resembles the US higher education system. Entrance to universities and other institutions of higher education is dependent upon the possession of a high school graduation certificate, and upon the results of the National Secondary Achievement Test (NSAT) in some cases, or upon the results of their own entrance examinations in many colleges and universities. NSAT is administered to fourth-year high school students to measure the quality of the individual institutions they are attending. It was not designed or intended as an admission test, but has nonetheless served the purposes of some institutions. Privately administered testing programs through the Center for Educational Measurement (CEM) are also widely used by colleges for admissions purposes. The most common tests are the College Scholastic Aptitude Test (CSAT) and the Admission Test for Colleges and Universities (ATCU). Typical school age during college years ranges from 16-21 years old.

Dollan (1991) stated that Filipinos have a deep regard for education, which they view as a primary avenue for upward social and economic mobility. From the onset of United States colonial rule, with its heavy emphasis on mass public education, Filipinos internalized the American ideal of a democratic society in which individuals could get ahead through good education. Middle-class parents make tremendous sacrifices in order to provide secondary and higher education for their children. Consistently, Sandoval et al (1998) surveyed 2,700 Filipino youth and found that $98 \%$ rated "having a good education" as being "very/rather important." The same survey indicated that having a good education was perceived as important as "having a good marriage and family life" and "being able to find steady work." It was perceived to be slightly more important than "being successful in work" and finding meaning and purpose in life". The survey also found that Filipino youth expressed in high satisfaction with their educational experiences provided by the school.

In summary, from the above literature review, we can find out some similarities on how Koreans and Filipinos put emphasis on the significant value of education in their societies. However, certain differences arise on the part that Koreans compared to Filipinos puts emphasis on parental supervision on their children's academic life. As mentioned above, Koreans are more inclined to have tutors and resort to better ways on how to facilitate their learning, while Filipinos tend to be more dependent on the school system alone. It is also quite evident that the educational background of both countries is varied in terms of structure and demographics as well as the beliefs, practices and policies imposed on higher education systems. The present study hypothesized that cultural backgrounds and educational experiences establish significant differences between Korean and Filipino college students in SRL skills 


\section{Methods}

\subsection{Participants}

The participants of this study were 185 Korean and 209 Filipino college students. They were enrolled in undergraduate programs in each country. The Korean students came from a medium sized national university,-located in a rural area southeast far away about $250 \mathrm{~km}$ from Seoul, Korea, while the Filipino students came from a medium sized state university, located in the northern part of Manila Bay, Philippines.

Filipino students' socio-demographic data collected from the participants showed that 148 students among them were 16-19 years old, 53 students were 20-23 years old, and 8 students were 23 years old. In addition, they were enrolled in the third and fourth year education courses majoring in Mathematics, English, Technology and Home Economics, or Science and Physical Education.

On the other hand, the Korean students were comprised of participants whose ages range from 20-31 years old. 159 students among them were 20-23 years old, and 24 students were 24-27 years old. They were enrolled in the first and second year education courses majoring in Educational Technology, Ethics Education, English Education, Math Education, Computer Education, Information \& Electronics Education, or Mechanical Engineering Education.

\subsection{Research Design}

The present study employed a comparative descriptive research design. A survey was used to collect data from a self-report questionnaire administered to the participants in order to identify possible differences in SRL skills between Filipino and Korean college students.

\subsection{Instrumentation}

The Motivated Strategies for Learning Questionnaire (MSLQ) developed by Pintrich et al (1991) was used to assess students' self-regulated learning skills and motivational orientation. The MSLQ manual was obtained from University of Michigan NCRIPTAL under the supervision of Dr. McKeachie, one of the developers of the instrument. The MSLQ is a self-report instrument that assesses use of six motivation strategies and nine self-regulated learning skills. Students rated themselves on 81 items using a 7 point Likert scale from "Not at all true of me" to "Very true of me".

The first part of the instrument measures 6 motivational orientations, namely, intrinsic goal orientation, extrinsic goal orientation, control of learning beliefs, self-efficacy for learning and performance, and test anxiety. The second is composed of 9 scales related to SRL strategies included in the questionnaire. The scales are rehearsal, elaboration, organization, critical thinking, metacognitive self-regulation, time/study environmental management, effort regulation, and help seeking. A Korean version of the MSLQ was utilized as the instrument for participating Korean students (Kim, 2002; Kang, 2000). For the case of Filipino students, a pilot test with 30 students was conducted to establish the reliability of the MSLQ instrument in English version. The reliability of the instrument was .88, and its Korean version was .92 , respectively.

\subsection{Research Procedures}

The MSLQ was distributed to the participant during regular classroom. For the Filipino students, a colleague of the researcher assisted in the administration of the instrument. For the Korean students, the researcher was assisted by the office secretary in the administration of the instrument. The participants were not required to provide their names on the instrument assuring them of anonymity and confidentiality. There was no time limit for the completion of the survey. The students were instructed to take enough time to answer each item, and they were asked to give back the questionnaire to the proctor upon completion.

After test administration, the questionnaires were classified for data analysis. Encoding of the responses was done with MS Excel program. After data encoding, mean values were computed for each of 15 subscales under learning strategies. As stated in the manual for MSLQ, mean values such as within 4, 5, 6, and 7 are interpreted as high, while scores falling within 1, 2, and 3 are considered as low (Pintrich et al., 1991). Further quantitative methods of analyses were applied to examine differences between the Korean and Filipino students' responses on the 15 MSLQ subscales.

\subsection{Statistical Analysis}

Means and standard deviations were derived to gain initial analyses of data collected. In order to assess the significant differences of SRL skills between two groups of students, a t-test was applied to the scores acquired from 15 subscales with SPSS. The level of significance was set at .05.

\section{Results}

\subsection{Comparison of SRL Skills between Filipino and Korean College Students}

To compare the degree of SRL skills of Filipino and Korean college students, a MSLQ developed by Pintrich (1991) was administered. The result is presented at Table 1. As seen, it showed that there was a statistically significant 
difference in SRL skills between Filipino and Korean college students $(t=10.86, p<.05)$. This means that Filipino college students have higher self-regulated learning skills than Korean college students

\section{-Insert Table1 here-}

\subsection{Comparisons between Two Groups in Each Category of SRL Skills}

To identify possible differences in each category of SRL skills between two groups, three major categories of Printrich's SRL skills (1993) were analyzed: cognitive, metacognitive, and resource management skills. Cognitive skills include rehearsal, elaboration, and organization. Metacognitive self-regulation is planning, monitoring, and regulating skills. And resource management skills are environmental management, effort management, and help seeking.

Results yielded from MSLQ for each category of SRL skills between two groups are presented at Table 2. As seen, it showed that Filipino college students scored statistically significantly higher means on all categories of SRL skills than Korean. This means that Filipino college students possess higher cognitive, metacognitive, and resource management skills than Korean college students.

\section{-Insert Table 2 here-}

\section{Discussions}

This study aimed to identify possible differences between Filipino and Korean college students in the degree of self-regulated learning (SRL) skills. Results from this study showed that the former have statistically significantly higher degree of SRL skills than the latter. Moreover, the study also showed that Filipino students possessed significantly higher level on each of three categories of SRL skills than the Korean counterparts. That is, it was found that the Filipino college students possess greater cognitive, metacognitive, and resource management skills than Korean. Such results are unexpected for us, and raised interesting issues for cultural comparison studies in terms of differences in SRL skills. The followings might be explained as reasons for such results.

First, the differences in SRL skills between Filipino and Korean college students could be explained as cultural factors, such as social expectations, value and beliefs towards college education, and respect for authority. Cultural backgrounds have been reported as a differentiating factor in the degree of SRL skills (Chye et al., 1997; Pillay et al., 2000; Purdie, \& Hattie, 1996; Matthews et al., 2000). Koreans are more inclined to have private tutors and resort to better ways on how to facilitate their learning, while Filipinos tend to be more dependent on the school system alone. In addition, Gorell et al (1996) suggested that Korean students manifest higher self-regulation for their non-school activities such that they spend more time and efforts out of school activities. This is contrary to the case of Filipino students who are given more individual learning tasks, such as individual reports, projects and homework in their college year (Sandoval et al, 1998). Therefore, Filipino college students were more inclined to employ SRL skills than Korean.

Second, it is likely that the difference in educational backgrounds between two countries led to such results. The frequent awarding of academic honors in the Filipino educational system even at the earliest grade levels reflect the strong incentive value of social approval and recognition (Church \& Katigbak, 1992). Individual academic ranks are used to determine how well students perform inside the Filipino college classroom setting. Also, majority of state colleges in the Philippines implement a required high grade point average whereby students who fail to meet the requirement are not re-admitted for the next semester or school year. For example, students who are enrolled in an education course are required to maintain a high GPA and above to be able to stay in their chosen major of study. Students who can't afford to enroll in private schools because of high tuition fee rates usually study hard to continue their pursuit for college degrees despite strict requirements (CHED, 2005). The academic motivation of Filipino students shows a strong extrinsic or instrumental aspect, because improved economic status is a top priority (Lynch, 1993). Therefore, there is a common thinking among Filipinos towards a pragmatic instrumental value for college education, such that they believe that it is an essential factor towards attaining other important goals in their life (Bernardo, 2004; Dolan, 1991).

On the other hand, Korean students perceive that one of the most crucial points in their life is the college entrance process; but once they are admitted to college, few students normally fail out. Thus, a common perception is that college students are already headed for success in Korea. For many, after the intense work required to get into college, the college year is more like a vacation, and feels like a new kind of freedom. Students attend classes regularly but often little is demanded in the way of homework or learning activities. In addition, Confucian ideas of education explicitly dominate the school system yet, including an authoritarian concept of the faculty member's role, a tendency to rely on lectures rather than discussion, and a lack of openness to student challenge (Jung, \& Stinett, 2005; Lee et al., 2003). Taken together, it seems that Korean educational backgrounds and college situations are responsible for the lower SRL skills of their students, compared to Filipino college students' SRL skills.

Finally, it is also possible that the school year levels and the gender ratio of two groups participated in the study had effects upon the difference in SRL skills. Since the Filipino students are in the third and fourth year of college, it is 
expected that since their learning situations are different from Korean students who are in the first and second year, the former may require higher degree of SRL skills or motivation. This is consistent with Winne's findings which suggested that the nature of task students are asked to complete can influence the degree of SRL skills (1993). Pintrich et al (1994) also showed that both initial individual differences and aspects of classroom contexts (i.e. teacher behavior, nature of tasks) were related to changing levels of SRL skills. Also, gender might be another issue for the results. Whereas the Korean students participated at the study were mostly males, most of the Filipino students participated at the study were mainly females. Many studies show that female college students tend to be higher in study skills than male students (Niemverta, 1997; Pokay \& Blumenfield, 1990; Zimmerman \& Martinez-Pons, 1990; Wolters, 1999). However, it seems that further research should be conducted on the gender difference in the use of SRL strategies or study skills.

\section{Conclusions}

The present study attempted to compare self-regulated learning skills between Filipino and Korean college students. Comparisons were made across Pintrch's MSLQ (1993), which is a self-report instrument assessing motivation orientations and self-regulated learning skills. Based on results from the present study and discussions from the related studies, the following conclusions were drawn.

We found that there are significant differences in self-regulated learning skills of Filipino and Korean college students. Filipino students showed higher self-regulated learning skills, compared to the Korean counterpart. It was unexpected finding, which is to be further examined with different subjects.

The study suggests that socio-cultural factors, such as social expectations, values and beliefs towards college education and respect for authority, might be factors underlying the difference in the self-regulated learning skills of Filipino and Korean college students. The factors have been identified from the results of previous studies on self-regulated learning of each cultural group. Since the difference in the number of each gender also influenced the degree of Filipino and Korean students' SRL skills, further research should be conducted with the control of the participant number of each gender.

From findings of this study, proposed are a few of research ideas related to comparison study on the degree of students' self-regulated learning skills among the different cultural backgrounds or educational situations. First, it is required to testify the validity of the results for the different level of students. Second, findings which Filipino college students have greater skills of self-regulated learning are needed to identify if it is associated with higher academic achievements in school settings or not. Finally, since the different language version of The Motivated Strategies for Learning Questionnaire (Pintrich et al., 1991) was administered to measure self-regulated learning skills for both countries' students, it is necessary for further research to be done in its English version for both Korean and Filipino college students to control for language constraints from each country.

\section{References}

Boekaerts, M. (1997). Self-regulated learning: A new concept embraced by researchers, policy makers, educators, teachers, and students. Learning and Instruction, 7(2), 151 86.

CHED. (2005). Annual Report: Philippine Commission on Higher Education. [Online] Available: http://www.ched.gov.ph/ar2005 (October 1, 2007)

Chen, C., \& Stevenson, H. W. (1995). Culture and academic achievement: Ethnic and cross national differences. Advances in Motivation and Achievement, 9, 119 151.

Chye, S., Walker, A., \& Smith, D. (1997). Self-regulated learning in tertiary students: the role of culture and self-efficacy on strategy use and academic achievement. Paper presented to the Annual Conference '97 of the Australian Association for Research in Education. Brisbane, Australia.

Corno, L., \& Mandinach, E. (1983). The role of cognitive engagement in classroom learning and motivation. Educational Psychologist, 18, 88 100.

Dolan, R. E. (1991). Philippines: A country study. Washington: GPO for the Library of Congress. [Online] Available: http://countrystudies.us/philippines/ (May 4, 2007)

Dweck, C. S. (2002). Beliefs that make smart people dumb. In R. J. Sternberg (Ed.), Why smart people do stupid things, (pp.41 43). New Haven, CT: Yale University Press.

Garcia, T. (1995). The role of motivational strategies in self-regulated learning. In P. R. Pintrich (Ed.), Understanding self-regulated learning: New directions for teaching and learning, (pp. 29 42). San Francisco: Jossey-Bass.

Garner, R. (1990). When children and adults do not use learning strategies: Towards a theory of settings. Review of Educational Research, 60, 517 529.

Gitomer, D. H., \& Glaser, R. (1987). If you don't know it works on it: Knowledge, self-regulation and instruction. In R. 
E. Snow \& M. Farr (Eds.), Aptitude, learning and instruction: Cognitive and affective process analyses (pp. 301 325). Hillsdale, NJ: Erlbaum.

Kang, N. H. (2000). A Study on the process and effective factor of individual knowledge creation. Unpublished master thesis. Ewha Womens University, Korea.

Kim, S. E. (2002). Effects of self-regulated learning strategy in performing e-Learning project. Unpublished master thesis. Ewha Womens University, Korea.

Perkins, D. N. (1992). Technology meets constructivism: Do they make a marriage? In T. M. Duffy and D. H. Jonassen (Eds.) Constructivism and the technology of instruction: A conversation (pp.32 39). Hillsdale, NJ: LEA.

Perry, E., Phillips, L., \& Hutchinson, R. (2006). Preparing student teachers to support for self-regulated learning. Elementary School Journal, 106, 237 254.

Pillay, H., Purdie, N., \& Boulton-Lewis, G. (2000). Investigating Cross-cultural variation in conceptions of learning and the use of self-regulated strategies. Education Journal, 28(1), 77 84.

Pintrich, P. R. (1995). Understanding self-regulated learning. In P. R. Pintrich (Ed.), Understanding self-regulated learning (pp. 3 12). San Francisco: Jossey-Bass.

Pintrich, R., \& De Groot, E. (1990). Motivational and self-regulated learning components of classroom academic performance. Journal of Educational Psychology, 82, 33 40.

Pintrich, R., Smith, A., Garcia, T., \& McKeachie, W. J. (1991). A manual for the use of the Motivated Strategies for Learning Questionnaire (MSLQ). National Center for Research to Improve Postsecondary Teaching and Learning. Ann Arbor, MI: University of Michigan Press.

Purdie, N. (1995). Strategies for self-regulated learning: A cross-cultural comparison. Paper presented at the Annual Meeting of the American Educational Research Association, San Francisco, CA, April 18 22, 1995. [Online] Available: http://www.eric.ed.gov/ERICDocs/data/ericdocs2sql/content_storage_01/0000019b/80/14/1b/e5.pdf (February 14, 2007)

Purdie, N., \& Hattie, J. (1996). Cultural differences in the use of strategies for self-regulated learning. American Educational Research Journal, 33(4), 845 871.

Saljo, R. (1987). The educational construction of learning. In J. T. E. Richardson, M. W. Eysenk, \& D. W. Piper (Eds.), Student learning (pp. 101-108). London: Milton Keynes Open University Press.

Sandoval, G., Mangahas, M., \& Guerrero, L. (1998). The situation of the Filipino youth: A national survey. Proceedings of 14th world congress of sociology, working group 3/ Sociology of Childhood (pp.14 22). Montreal, Canada on July 26 August 1.

Savada, A., \& Shaw, W. (1992). South Korea: A country study. Federal Research Division. Washington, DC: Library of Congress.

Schunk, D. H., \& Zimmerman, B. J. (2008). Motivation and self-regulated learning: Theory, research and applications. New York: LEA.

Siu, S. F. (1992). Toward an understanding of Chinese American educational achievement (Report No. 2). Center on families, communities, schools, and children's learning. Rochester, NY: Rochester University.

Stevenson, H. W., \& Lee, S. Y. (1991). Contexts of achievement: A study of American Chinese and Japanese children. Monographs of the Society for Research in Child Development, 55(22), 1 2.

Stevenson, H. W., \& Stigler, J. W. (1992). The learning gap: Why our schools are falling and what we can learn from Japanese and Chinese education. New York: Simon \& Schuster.

Strom, R., Daniels, S., \& Leung, A. (1988). Parental expectations in Hong Kong. Journal of Instructional Psychology, 15(1), 12 16.

Tanaka-Matsumi, J., \& Marsella, A. (1976). Cross-cultural variations in the phenomenological experience of depression. Journal of Cross-Cultural Psychology, 7, 379 396.

Tynjala, P. (1997). Developing education students' conceptions of the learning process in different learning environments. Learning and Instruction, 7(3), 277 292.

Vanderstoep, S. W., Pintrich, P. R., \& Fagerlin, A. (1996). Disciplinary differences in self-regulated learning in college students. Contemporary Educational Psychology, 21(4), 345 362.

Weidman, J., \& Park, N. G. (2000). Higher education in Korea: Tradition and adaptation. New York: Falmer Press.

Winne, P. H., \& Perry, N. E. (2000). Measuring self-regulated learning. In P. Pintrich, M. Boekaerts, \& M. Seidner 
(Eds.), Handbook of Self-Regulation (pp. 531 566). Orlando, FL: Academic Press.

Wollam, J. (1992). Equality versus excellence - The South Korean dilemma in gifted education. Roeper Review, 14(4), $212 \sim 217$.

Zimmerman, B. J., \& Schunk, D. (2001). Self-regulated learning and academic achievement. Mahwah, NJ: Erlbaum.

Table 1. Mean, SD \& Results of t-test for Filipino \& Korean Students' SRLS

\begin{tabular}{|c|c|c|c|c|}
\hline & $F(n=209)$ & $\mathrm{K}(\mathrm{n}=185)$ & \multirow{2}{*}{$\mathrm{df}$} & \multirow{2}{*}{$\mathrm{t}$} \\
\hline & $\mathrm{M}(\mathrm{SD})$ & $\mathrm{M}(\mathrm{SD})$ & & \\
\hline SRLS & $4.92(.429)$ & $4.38(.52)$ & 392 & $10.86^{*}$ \\
\hline
\end{tabular}

Note: $\quad$ SRLS: Self-Regulated Learning Skills

F: Filipino Students

K: Korean Students

Table 2. Mean, SD \& Results of t-test for SRL' Categories

\begin{tabular}{|c|c|c|c|c|}
\hline \multirow{2}{*}{ Category } & $F(n=209)$ & $\mathrm{K}(\mathrm{n}=185)$ & \multirow{2}{*}{$\mathrm{df}$} & \multirow{2}{*}{$\mathrm{t}$} \\
\hline & $\mathrm{M}(\mathrm{SD})$ & $\mathrm{M}(\mathrm{SD})$ & & \\
\hline $\mathrm{CS}$ & $5.14(.67)$ & $4.49(.70)$ & 392 & $9.28 *$ \\
\hline MS & $4.94(.54)$ & $4.35(.57)$ & 392 & $10.46^{*}$ \\
\hline $\mathrm{RM}$ & $4.71(.41)$ & $4.27(.47)$ & 392 & $9.86^{*}$ \\
\hline
\end{tabular}

Note: CS: Cognitive Skills $\quad$ MS: Metacognitive Skills

RM: Resource Management

F: Filipino Students K: Korean Students 